\title{
Progressive systemic sclerosis of the internal anal sphincter leading to passive faecal incontinence
}

\author{
A F Engel, M A Kamm, I C Talbot
}

\begin{abstract}
Two female patients aged 62 and 44 years with progressive systemic sclerosis and passive faecal incontinence are described. Both had the typical gut motility disorders of dysphagia, heartburn, and constipation. Anorectal physiology tests showed a low resting pressure in both and an absent rectoanal inhibitory reflex in one. In both patients anal endosonography showed a thin internal anal sphincter with changed reflectivity suggestive of fibrosis. In both patients anorectal sensation and pudendal nerve function were normal. Histological examination of the rectum in one patient showed collagenous replacement of the rectal muscularis propria with prominent atrophy of the musculature. This study suggests that the internal sphincter may be selectively affected by progressive systemic sclerosis, which may lead to passive faecal incontinence.

(Gut 1994; 35: 857-859)
\end{abstract}

Replacement of the oesophageal and gastrointestinal muscularis propria by fibrous tissue is well recognised in progressive systemic sclerosis (PSS) and may lead to upper gut dysmotility, chronic intestinal pseudo-obstruction, and constipation. ${ }^{1}$ Only recently has faecal incontinence been described in PSS and linked to pathological changes affecting the internal anal sphincter rather than to bacterial overgrowth diarrhoea and overload of the sphincters. ${ }^{2}$ Morphological evidence has been lacking. We present two case histories and provide endosonographic and morphological evidence for internal and sphincter dysfunction in PSS.

Physiology

M A Kamm

and Pathology, St Mark's Hospital, London I C Talbot

Correspondence to:

Dr M A Kamm, Department of Physiology, St Mark's Hospital, City Road, London ECIV 2PS.

Accepted for publication 6 October 1993

\section{Case histories}

HISTORIES

Two patients with PSS complaining of passive faecal incontinence were investigated by anorectal physiology studies and anal ultrasound and histological examination in one case.

Anorectal physiology tests in both patients showing low resting pressure and absence of the rectoanal inhibitory reflex in patient $A$. Other tests were normal, excluding an external sphincter structural or neuropathic cause for the incontinence

\begin{tabular}{llcc}
\hline & Normal & Patient $A$ & Patient $B$ \\
\hline Rectoanal inhibition reflex & Present & Absent & Present \\
Resting pressure $\left(\mathrm{cm} / \mathrm{H}_{2} \mathrm{O}\right)$ & $>60$ & 15 & 20 \\
Squeeze pressure $\left(\mathrm{cm} / \mathrm{H}_{2} \mathrm{O}\right)$ & $>80$ & 80 & 200 \\
Threshold volume $(\mathrm{ml}$ air) & $0-40$ & 30 & 40 \\
Urgency volume (ml air) & $24-98$ & 90 & 60 \\
Max tolerated volume $(\mathrm{ml}$ air) & $125-337$ & 140 & 120 \\
Mean pudendal latency $(\mathrm{ms})$ & $1 \cdot 8-2 \cdot 2$ & $2 \cdot 1$ & $2 \cdot 2$ \\
Single fibre density & $1 \cdot 4-1 \cdot 6$ & $1 \cdot 45$ & $1 \cdot 4$ \\
Anal electrosensitivity $(\mathrm{mA})$ & $0-10 \cdot 2$ & $3 \cdot 9$ & $9 \cdot 8$ \\
Rectal electrosensitivity $(\mathrm{mA})$ & $2-34$ & 15 & $17 \cdot 4$ \\
\hline
\end{tabular}

Patient A was a 62 year old woman with a nine year history of PSS. She had a five year history of progressive dysphagia and heartburn and three years of progressive passive incontinence to liquid stool and flatus. She also had periods of constipation. She had had three uncomplicated vaginal deliveries and underwent a right hemicolectomy for adenocarcinoma in 1982 with no signs of recurrent disease to date. Recent colonoscopy showed some wide necked sigmoid diverticula and no sign of recurrent cancer. She was treated with oral loperamide, which considerably improved her faecal incontinence.

Patient B was a 44 year old woman with a seven year history of PSS. She had a 20 year history of constipation, dysphagia, and heartburn and five years of worsening passive faecal incontinence for solid stool and flatus. She had difficulty in opening her bowels and initiating micturition. She had had three uncomplicated vaginal deliveries. Proctosigmoidoscopy showed signs of rectal prolapse, which was confirmed at defecography. Barium enema showed wide necked sigmoid diverticula. A rectopexy was proposed but at operation stercoral perforation of two low sigmoid diverticula was found and a two staged anterior resection was performed.

Both patients had the typical skin changes of PSS, telangiectasias, and Raynaud's phenomenon. The diagnosis of PSS conformed to published criteria. $^{3}$

\section{ANORECTAL PHYSIOLOGICAL STUDIES (TABLE)}

Both patients had a low resting anal pressure. The rectoanal inhibition reflex could not be elicited in patient A. In both patients all other physiology tests were normal.

\section{ANAL ULTRASOUND}

Both patients had an intact external sphincter. In both patients the internal sphincter was thin and appeared hyperechoic (Fig 1). The width (mean of left and right lateral internal anal sphincter width) of the internal anal sphincter in patient $A$ and $B$ was 1.3 and $1 \mathrm{~mm}$ respectively. The normal value in our unit is $2.4-2.7 \mathrm{~mm}$ in patients younger than 55 years and 2.8-3.4 mm in patients older than 55 years.

HISTOLOGICAL STUDIES (FIG 2)

A longitudinal section of the upper rectum from patient B showed noticeable patchy thinning of the muscularis propria, with fibrous replacement affecting both the circular and longitudinal layers of smooth muscle. Furthermore, the extent of fibrous replacement was greater than initially - expected; although part of the muscle structure 
Figure 1: (A) Anal ultrasound of normal internal anal sphincter (width $2.4 \mathrm{~mm}$ ); (B) abnormal internal anal sphincter of patient $B$ (width $<1 \mathrm{~mm}$ ). Arrows point to internal anal sphincter.
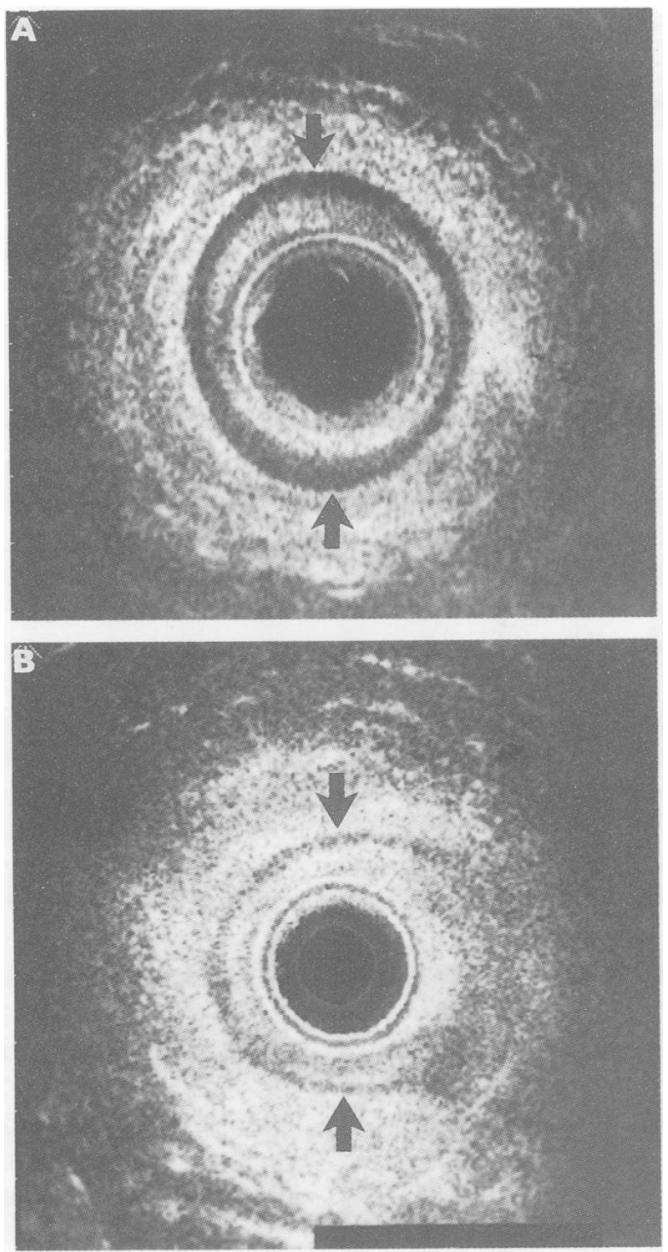

seemed normal on haematoxylin and eosin staining, trichrome staining (Martius scarlet blue) for collagen showed almost complete replacement by collagen.

\section{Discussion}

It has been assumed that the gastrointestinal manifestations of PSS, which usually appear after the skin symptoms, are only late sequelae of PSS. ${ }^{4}$ Recent studies have shown, however, that there may be early participation of gastrointestinal smooth muscle in PSS before clinical symptoms. ${ }^{5}$ In addition sclerosis of the gastrointestinal muscularis propria is more common in PSS necropsies than clinical signs would suggest. ${ }^{6}$

Faecal incontinence is less well recognised and its incidence in PSS is unknown. In two studies of 363 cases $^{4}$ and 727 cases $^{7}$ of PSS faecal incontinence was not mentioned. Other studies

Figure 2: Patient A Longitudinal section of sigmoid colon shows patchy thinning of muscularis propria, with fibrous replacement of muscle layers, affecting circular layer of smooth muscle. Smooth muscle may seem normal (arrow), but in the lower part of the Figure (if followed to the left of normal muscle) is almost completely replaced by collagen. (Trichrome, Martius scarlet blue, original magnification $\times 12$ ). that have particularly looked at patients with PSS and anorectal abnormalities have also not mentioned the incidence of faecal incontinence in PSS. ${ }^{28}$ Physiological abnormalities of the anorectum may be found in PSS even before clinical symptoms and recent studies have focused on anorectal physiological findings in patients with PSS. The physiological abnormalities include reduced rectal compliance, ${ }^{9}$ low resting pressure but normal squeeze pressure, and absence of the rectoanal inhibition reflex in up to 71 per cent of patients. ${ }^{28}$ Also in PSS patients the duodenal filling reflex and the gastrocolic reflex may be absent. In the early stages of the disease there may be cholinergic neuropathic changes leading to the abolishment of these reflexes. ${ }^{10-12}$ In later stages collagenous replacement of smooth muscle aggravates muscular dysfunction. The rectoanal inhibition reflex was absent in 71 and 50 per cent of patients in two recent studies. ${ }^{28}$ When resting pressure is very low it is difficult or even impossible to elicit an inhibition reflex and this may explain some of the interstudy differences.

In PSS affected cells may accumulate excessive collagen ${ }^{13}$ and the essential histological feature of gastrointestinal participation in PSS is fibrous replacement of the muscularis propria leading more often to atrophy than to fibrosis. ${ }^{6}$ In contrast with primary intestinal myopathy there is no vacuolar degeneration of smooth muscle. ${ }^{14}$ Striated muscle is largely unaffected in PSS. ${ }^{6}$ The internal anal sphincter is a direct continuation of the circular muscle layer of the rectum and is therefore susceptible to the same involvement by PSS. In normal people the internal anal sphincter contributes 85 per cent to resting pressure and in the absence of external sphincter abnormality or other reasons for smooth muscle dysfunction a drop in resting pressure in both our patients reflects internal anal sphincter dysfunction. ${ }^{15} \mathrm{~A}$ certain degree of fibrosis of the internal anal sphincter is a normal age related phenomenon and leads to thickening of the internal ana sphincter. ${ }^{16}$ In both our patients anal endosonography showed a very thin internal anal sphincter with only a little smooth muscle left suggesting severe PSS involvement. Although fibrosis has possibly caused this internal anal sphincter atrophy, vasculopathy of arterioles is common in PSS and fibrous replacement of the internal anal sphincter could be partly ischaemic in origin. This would account for the atrophy rather than thickening of the internal anal sphincter that we found in these patients.

Colonic perforation ${ }^{18}$ and rectal prolapse ${ }^{8}$ have been previously described to occur in PSS and were present in one of our patients. Wide, square necked diverticula are thought to be fairly specific to scleroderma and were present in both our patients. ${ }^{1}$ Again this morphological feature would be consistent with the effect of smooth muscle atrophy.

In conclusion the internal anal sphincter may be affected in PSS causing passive faecal incontinence and this symptom should be sought in patients with PSS. Anorectal physiology testing and ultrasound can be used to characterise function and morphology of the internal anal sphincter leading to specific treatment, such as loperamide. ${ }^{19}$ 
This work was presented at the BSG meeting in March 1993 and appeared in abstract in Gut 1993; 34 (suppl 1): S61.

M A Kamm is supported by the St Marks' Research Foundation.

1 Cohen S, Laufer I, Snape WJ, Shiau YF, Levine GM, Jimenez $\mathrm{S}$. The gastrointestinal manifestations of scleroderma: pathogenesis and management. Gastroenterology 1980; 79 $150-66$

2 Chiou AWH, Lin JK, Wang FM. Anorectal abnormalities in progressive systemic sclerosis. Dis Colon Rectum 1989; 32: 417-21.

3 Massi AT, Rodnan GP, Mediger TA. Preliminary criteria for the classification of systemic sclerosis (scleroderma). Arthritis Rheum 1980; 23: 518-90.

4 Poirier TJ, Rankin GB. Gastrointestinal manifestations of systemic sclerosis based on a review of 364 cases. systemic sclerosis based on a
Am $\mathcal{F}$ Gastroenterol $1972 ; 58: 30-44$.

5 Hamel Roy J, Devroede G, Arkan P, Tetreault C, Duranceau A, Menard HA. Comparative esophageal and anorectal motility in scleroderma. Gastroenterology $1985 ; 88: 1-7$.

6 D'Angelo UA, Fries JF, Massi AT, Shulman CE. Pathologic observations in systemic sclerosis (scleroderma). A study of fifty eight autopsy cases and fifty eight matched controls. Am F Med 1969; 46: 428-40.

7 Tuffanelli DL, Winkelman RK. A clinical study of 727 cases. Arch Dermatol 1961; 84: 49-61.

8 Leighton JA, Valdovinos MA, Pemberton JH, Rath DM, Camilleri M. Anorectal dysfunction and rectal prolapse in progressive systemic sclerosis. Dis Colon Rectum 1993; 36: $182-5$.

9 Whitehead WE, Taitelbaum G, Wigley FM, Schuster MM.
Rectosigmoid motility and myoelectric activity in progressive systemic sclerosis. Gastroenterology 1989; 96: 428-32. 10 Cohen S, Fisher R, Lipschutz W. The pathogenesis of esophageal dysfunction in scleroderma and Raynaud's disease. 7 Clin Invest 1972; 51: 2663-8.

11 Sonnex C, Paice E, White AG. Autonomioc neuropathy in systemic sclerosis: a case report and evaluation of six patients. Ann Rheum Dis 1986; 45: 957-60.

12 Greydanus MP, Camilleri M. Abnormal postcibal antral and small bowel motility due to neuropathy or myopathy in systemic sclerosis. Gastroenterology 1989; 96: 110-5.

13 Buckingham RB, Prince RK, Rodnan GP, Taylor F. Increased collagen accumulation in dermal fibroblast cultures from patients with progressive systemic sclerosis (scleroderma). 7 Lab Clin Med 1978; 92: 5-21.

14 Schuffler MM, Beegle RG. Progressive systemic sclerosis of the gastrointestinal tract and hereditary hollow visceral the gastrointestinal tract and he disorders of of intestinal smooth muscle. Gastroenterology 1979; 77: 664-71.

15 Frenckner $B$, von Euler $C$. Influence of pudendal block on the function of the anal sphincters. Gut 1975; 16: 482-9.

16 Klosterhalfen B, Offner F, Topf N, Vogel P, Mittermayer C. Sclerosis of the internal anal sphincter: a process of aging. Dis Colon Rectum 1990; 33: 606-9.

17 Leroy EC. Scleroderma (systemic sclerosis). Textbook of rheumatology. New York: W B Saunders, 1985: 1183-205.

18 Robinson JC, Teitelbaum SL. Stercoral perforation of the sclerodermatous colon: report of two cases and review of the literature. Dis Colon Rectum 1974; 17: 622-32.

19 Read MG, Read NW, Barber DC, Duthie HL. Effects of loperamide on anal sphincter function in patients complaining of chronic diarrhoea with faecal incontinence and urgency. Dig Dis Sci 1982; 27: 807-14. 